\title{
O Grupo Globo e as restrições à autonomia da rádio CBN1
}

\section{Grupo Globo and the restrictions on the autonomy of $\mathrm{CBN}$ radio}

Patrícia Maurício e Creso Soares Junior ${ }^{3}$

1 Trabalho apresentado no GP Economia Política da Informação, Comunicação e Cultura, XVIII Encontro dos Grupos de Pesquisas em Comunicação do $41^{\circ}$ Congresso Brasileiro de Ciências da Comunicação (Intercom). Pós-Graduação em Comunicação (PPGCom) da Pontifícia Universidade Católica do Rio de Janeiro (PUC-Rio). E-mail: patriciamauricio@puc-rio.br. 


\section{Resumo}

A Central Brasileira de Notícias (CBN), em seus primeiros dez anos de vida, saiu de uma relativa autonomia editorial para a tutela do Grupo Globo. A organização empresarial percebeu a influência que a emissora passou a ter na política e na economia do país e decidiu adequá-la à política empresarial do grupo. O lucro foi outro fator preponderante para as mudanças na emissora nesse período. Para este artigo foram feitas entrevistas com profissionais que trabalharam durante esses anos na emissora em cargos de comando. Além disso, foi utilizada bibliografia para o embasamento teórico, com destaque para César Bolaño e Valério Brittos.

Palavras-chave

Radiojornalismo, autonomia, Grupo Globo, privatização do conhecimento.

\section{Abstract}

The radio station Central Brasileira de Notícias (CBN), in its first ten years of existence, left a state of relative editorial independence and became part of Grupo Globo. The business organization perceived the previous influence of the station in the politics and economy of the country and decided to adapt it to the corporate policy of the group. Profit was another main factor for the changes in the station in that period. For this article, interviews were conducted with professionals who worked during these years on CBN in head positions. Bibliography was used as theoretical framework, mainly that of authors César Bolaño and Valério Brittos.

\section{Keywords}

Journalism, autonomy, Grupo Globo, privatization of knowledge. 


\section{Introdução}

Em primeiro de outubro de 1991 entrava no ar a Central Brasileira de Notícias (CBN), mais uma das rádios do Grupo Globo, na época chamado de Organizações Globo, primeira emissora do país a apostar no formato all news. No Rio de Janeiro, a nova rádio entrou no dial 1.180 AM, no lugar da Eldorado; em São Paulo, substituiu a Excelsior em 780 AM. Em 1995, a CBN-SP passou para FM, no lugar da Rádio X, na frequência 90,5; já a CBN-RJ foi para FM apenas em 2005, encerrando as transmissões da Globo FM no dial 92,5. Todas as emissoras pertenciam ao Sistema Globo de Rádio (SGR), que tinha estações próprias também em Brasília, Belo Horizonte e Recife, tanto na banda de AM, quanto na FM (TAVARES; FARIA, 2006).

Neste artigo, focamos os primeiros dez anos dessa emissora, que passou a ter grande alcance nacional ao se coligar com afiliadas, que retransmitem o conteúdo nacional gerado pela rádio e produzem conteúdo próprio nos horários destinados à produção local. Por meio de entrevistas com jornalistas que ocuparam cargos de chefia na emissora, bibliografia produzida pelos próprios gestores e bibliografia teórica pertinente, pretendemos mostrar como e por que a CBN saiu de uma posição de surpreendente autonomia para os padrões de homogeneização e hegemonia do Grupo Globo para uma de submissão e aceitação do controle ideológico do conteúdo.

Inspirada num modelo americano, a CBN foi ideia do filho mais novo do fundador, Roberto Marinho, o vice-presidente das Organizações Globo, José Roberto Marinho, que chegou ao SGR em 1986 para acompanhar mais de perto a empresa (MARINHO, 2006). O Grupo Globo pensava em realizar uma mudança administrativa na unidade de radiodifusão, por isso José Roberto se encarregou das FM musicais. No entanto, o grupo empresarial dos Marinho nasceu de um jornal, portanto assuntos jornalísticos eram sensíveis aos acionistas: 
porque a praça Rio de Janeiro não tinha nada semelhante. Embora a Rádio Jornal do Brasil fosse uma referência, não era uma emissora jornalística de serviço, era até mais intelectualizada, com grandes programas de entrevista. (MARINHO, 2006, p. 16-17)

Apesar de não existirem estações de rádio all news à época, pouco antes da criação da CBN já tinha havido, no Rio de Janeiro, as experiências do programa Panorama Brasil, na rádio Panorama FM $(90,3)$, com uma hora e meia seguida de jornalismo, e da Rádio JB AM (940), com duas horas seguidas, ambas no horário nobre do rádio.

Quando a CBN foi lançada, o oligopólio do Grupo Globo detinha mais de $50 \%$ das verbas publicitárias do país (MEDITSCH, 2001). O início desse império das comunicações foi o jornal O Globo, fundado por Irineu Marinho em 1925. Com a morte do pai, o primogênito, Roberto, tomou conta dos negócios após um período de maturação empresarial. A Rádio Globo foi fundada em 1944 e a TV Globo em 1965.

O Grupo Globo cresceu de forma significativa durante a ditadura militar (1964-1985). O governo Costa e Silva assinou um decreto isentando as empresas de rádio e televisão do pagamento de impostos sobre equipamentos importados. Somado a isso, os militares renovaram o parque de comunicações brasileiro e, em fevereiro de 1970, o país estava praticamente ligado por um sistema de transmissão por micro-ondas. Esse pacote de medidas do governo ditatorial permitiu que o Grupo Globo investisse na modernização dos equipamentos, liquidasse uma dívida com o grupo americano Time-Life, contraída na época da inauguração da TV, e se transformasse na primeira rede nacional de televisão (GASPARI, 2002).

Empresários das comunicações que se opuseram ao regime, como Samuel Wainer, dono do jornal Última Hora, e Niomar Moniz Sodré Bitencourt, proprietária do Correio da Manhã, foram cerceados política e economicamente pelos militares. Isso acontecia concomitantemente ao florescimento do maior grupo de comunicação do Brasil. Roberto Marinho foi aliado de primeira hora dos militares que tomaram o poder em 1964. "Com maneiras gentis e um senso de lealdade fora do comum 
na política brasileira, era um adversário feroz pela astúcia, um aliado insuperável pelo sentido de oportunidade. A ditadura transformava-se em milagre e a televisão em cores, em seu ícone" (GASPARI, 2002, p. 217).

As ações dos governos militares no campo das telecomunicações não ajudaram apenas a televisão. O rádio também se reestruturou com o começo das operações em frequência modulada (FM) (FERRARETTO, 2001). No início dos anos 1970, as emissões em FM eram desorganizadas, mas a ditadura tornou sua expansão uma prioridade.

Como parte da estratégia governamental de interiorização da radiodifusão, a FM, apesar do alcance reduzido de suas ondas, servia à meta de dotar as cidades de uma estação. [...] A expansão das FMs também atendia a objetivos políticos: "integrar e desenvolver o país" e "resguardar o território nacional e os valores culturais" combatendo a penetração de emissoras estrangeiras. (DEL BIANCO, 1993, p. 142 apud FERRARETTO, 2001, p. 156-157)

As concessões de rádio passaram a ser uma moeda de troca política dali em diante. Tanto é que, durante a Assembleia Nacional Constituinte (1986-1988), o licenciamento de novas emissoras foi usado, por exemplo, para que o mandato de José Sarney (1985-1990) fosse prorrogado. Isto fez com que a informação no rádio ficasse ainda mais dependente do poder político, como explica Meditsch:

Desta forma, o oligopólio dos meios de comunicação, cimentado no regime militar - nove famílias controlam $90 \%$ da informação divulgada no país (Costa 1991:223) - resistiu incólume à campanha pela democratização da comunicação social, durante a Assembleia Nacional Constituinte 19861988. (MEDITSCH, 2001, p. 127)

No início dos anos 1990, só na cidade do Rio de Janeiro, a família Marinho era dona de cinco canais de rádio: 92,5 e 98,1 FM e 860, 1180 e 1220 AM. Pelo discurso de José Roberto Marinho, a CBN poderia representar o ponto de partida da reestruturação que os acionistas queriam fazer nas rádios de sua propriedade. A TV Globo tinha a força econômica na organização e o jornal $O$ Globo dava o prestígio político. Nesse processo, as emissoras de radiodifusão 
ficaram um pouco esquecidas. Marinho explica o direcionamento que pretendia dar ao novo produto.

Com a entrada de Jorge Guilherme para a direção de jornalismo do SGR, em 1989, pudemos tocar o projeto. Ele era o homem certo, na hora certa, até porque vinha com a experiência da Radiobrás e da Agência O Globo de Notícias. Uma das nossas maiores preocupações era dar ênfase à prestação de serviço, que já caracterizava o jornal O Globo desde o início de sua história. (MARINHO, 2006, p. 16-17)

Soloski (1993) explica o funcionamento de um sistema como o Grupo Globo. As organizações são sistemas complexos, compostos por subsistemas interrelacionados e interligados. O oligopólio dos Marinho tinha veículos impressos, televisivos e radiofônicos, sendo necessário incluir a rádio à unidade da política empresarial da organização.

Gerente de jornalismo da CBN até janeiro de 2001 e integrante da equipe que inaugurou a emissora, em 1991, Marco Antônio Monteiro explica que, no início, a ideia era lançar uma emissora jornalística sem vínculo com o nome Globo. Para ele, um dos motivos pode ter sido o desgaste provocado com a edição do debate entre os candidatos Fernando Collor de Mello e Lula no segundo turno da eleição presidencial de 1989.

A orientação é que a gente ia lançar uma rádio jornalística sem nenhuma vinculação com as Organizações Globo. Não sei se eles achavam que a rádio vinha manchada com aquele episódio do debate Collor $x$ Lula, pois estávamos em 1991. O Zé Roberto Marinho tinha voltado dos Estados Unidos com a ideia de uma rádio all news. Na época cada irmão cuidava de um segmento, e coube ao mais novo deles as rádios. O fato é que, quando o Jorge Guilherme foi implementar o projeto, não podia ter nenhuma relação com a Rádio Globo. Os carros eram caracterizados como CBN, os repórteres que entravam na CBN não eram os mesmos da Rádio Globo. (Informação verbal) ${ }^{4}$ 
O objetivo das Organizações Globo era aprimorar o controle nas empresas de radiodifusão do grupo e garantir a sobrevivência do negócio.

No processo histórico de expansão do capitalismo, a esfera econômica mantém uma posição predominante, subsumindo, no seu movimento, todas as outras. Ao mesmo tempo em que fica claro que essa determinação pelo econômico só se verifica na medida em que o capital consegue impor sua lógica de expansão ao conjunto de uma sociedade. [...] Nada mais esclarecedor do verdadeiro impulso civilizatório do capital que a observação de que a tendência irrefreável da concorrência ao monopólio pode ser extrapolada do âmbito econômico, em que foi precisamente formulada por Marx, para o campo mais amplo da cultura. A evidência mais clara desse fenômeno talvez seja o próprio pressuposto da homogeneidade sobre o qual a indústria cultural assenta um dos seus pilares. (BOLAÑO; BRITTOS, 2007, p. 50-51)

Apesar do nascimento da nova emissora ter sido acompanhado de perto, os jornalistas que dirigiam a CBN nos primórdios gozavam de certa autonomia, a qual, mais tarde, foi suprimida. Uma das primeiras coberturas em que a CBN se destacou foi a da comissão parlamentar de inquérito (CPI) do PC Farias, que investigava as ações do tesoureiro de campanha e eminência parda do Governo Collor (1990-1992). Bucci entende que, ao transmitir os depoimentos, a CBN reabilitou o espaço público brasileiro.

Dos anos 1970 em diante, o Brasil virou sinônimo de televisão. Em particular virou sinônimo de Rede Globo [...] o que não estava na TV não tinha tido lugar no mundo. Em função desse padrão tecnológico, decorrente da poderosa centralidade que a instância da imagem ao vivo assumiu na comunicação social, a televisão se converteu na arena mais luminosa da nacionalidade [...]. A CBN ajudou a mudar este estado de coisas. Ela não revogou a prevalência da imagem, mas mudou o quadro. [...] Desse modo, passou a concorrer em pé de igualdade com todos os outros veículos. Sem risco de exagero, é possível afirmar que, naquele ano de 1992, o espaço público brasileiro, mais que profundidade, ganhava complexidade. (BUCCI, 2011, p. 10-14)

A CBN, ao longo do tempo, promoveu uma troca de radialistas por jornalistas na área de conteúdo, mantendo os radialistas na produção, locução de jornais 
e apresentação de programas. Primeiramente, isso aconteceu em postos de comando, como diretores, gerentes, coordenadores, depois na apresentação dos programas e na produção. Locutores comerciais continuaram sendo radialistas ${ }^{5}$. Jornalistas e radialistas são profissionais diferentes: à época, do jornalista era exigido diploma de Jornalismo, do radialista não. A justificativa principal para essa troca de profissionais é que a CBN é uma emissora jornalística, como explica a ex-gerente de recursos humanos do SGR, Mônica Almeida:

Pela regulamentação da profissão de radialista, o acúmulo de função somente é permitido dentro do mesmo setor. Não é permitido o acúmulo de funções que pertençam a setores diferentes. Sendo assim, na letra fria da lei, um produtor não pode receber acúmulo para ser também locutor. Deveria ter dois contratos distintos. No caso de jornalista, não há essa restrição. O jornalista pode apurar, escrever, falar, apresentar etc. A CBN só tinha jornalistas na área de conteúdo, por ser uma emissora essencialmente jornalística. Na parte técnica, a CBN tinha radialistas. (Informação verbal) ${ }^{6}$

A proposta era clara: a CBN era uma rádio jornalística, feita por jornalistas. Mariza Tavares, que foi diretora executiva da emissora de 2002 a 2016, deixa evidente o que se buscava nos profissionais que atuariam na CBN:

Um dos grandes mitos do rádio que, felizmente, a CBN ajudou a derrubar é que a bela voz é a principal ferramenta do profissional. Voz boa ajuda, sem dúvida, mas não é fundamental. O bom texto é indispensável na produção de conteúdo editorial de qualidade. (TAVARES, 2006, p. 51)

\section{Radiojornalismo e a construção da realidade}

Os meios de comunicação comerciais distribuem conteúdo que atende aos interesses do poder e o aparato midiático espalha-se pelos mais diversos espaços, passando a integrar a sociabilidade. A mídia conta com uma legitimidade forjada na própria engrenagem comunicacional: 
Apresenta-se todo o aparato midiático como o próprio poder, não só por seu papel social (ou a quem serve), mas porque assim é visto pela sociedade, que o identifica como algo superior, portador/definidor da realidade (e não uma representação desta), revelador da verdade e responsável pela criação das autênticas autoridades dos tempos atuais. (BRITTOS; GASTALDO, 2006, p. 121-122)

Como já foi mencionado, no início do anos 1990, os dirigentes da CBN gozavam de relativa autonomia em relação ao comando do Grupo Globo. De 1991 a 1994, a impressão geral nas emissoras era de que poucas pessoas se importavam com o SGR na holding dos Marinho. Um exemplo disso era o tratamento dado ao então governador do Rio de Janeiro, Leonel Brizola. Inimigo declarado de Roberto Marinho, o nome de Brizola não era citado na Rádio Globo, no jornal e na TV. Só se referiam ao político como governador. No entanto, na CBN, a questão foi superada desde o início:

Nos dois primeiros anos, a lógica da CBN era de que "não damos opinião, damos informação". Quando a informação tinha dois lados, você dava os dois lados. As pessoas se admiravam com o fato de ser uma emissora do Sistema Globo. Por exemplo, o PT tinha uma bancada muito atuante com Suplicy e Mercadante e eles tinham espaço na CBN. A CBN tinha independência. (Informação verbal) ${ }^{7}$

A CBN começou a ganhar prestígio em Brasília. Políticos e formadores de opinião passaram a prestar atenção na emissora durante a CPI do PC Farias. A jornalista Miriam Leitão relembrou o momento em que percebeu a dimensão de seus comentários na CBN: "Um dia recebi um telefonema de um contrariado ministro do Supremo: Miriam, hoje estava fazendo a barba, quando ouvi você me criticando... Fiquei sabendo assim que o ministro não desgruda da CBN nem no banheiro. Bom saber" (LEITÃO, 2006, p. 95). A CBN tinha a confiança dos formadores de opinião e políticos, mas comercialmente era um fracasso, como relata o ex-diretor geral do SGR, Rubens Campos: 
Assumi a diretoria comercial do Sistema Globo de Rádio em outubro de 1998. A empresa operava com grande prejuízo. Em pouco tempo de conversa com os demais diretores descobri que havia um dilema instalado no sexto andar da Rua do Russel, na Glória, no Rio de Janeiro: uma consultoria de negócios havia identificado o foco do problema: era a CBN, cujo prejuízo era maior do que todo o lucro gerado pelos outros negócios. Ora, como a previsão dessa consultoria era a de que a CBN somente atingiria o ponto de equilíbrio em 2010, a decisão sensata seria fechá-la. Acreditem, a CBN ia sair do ar. (CAMPOS, 2006, p. 57)

Mariza Tavares corrobora as palavras de Rubens Campos: "O reconhecimento da marca demorou um pouco. Profissionais que estão na emissora desde a sua criação como Heródoto Barbeiro [...] lembram que, nos primeiros anos, tanto a audiência, quanto o retorno publicitário eram praticamente nulos" (TAVARES, 2006, p. 46). A solução para a $C B N$ foi o corte na folha salarial. Assim, na virada de 1997 para 1998, a emissora passou de duzentos para menos de cem profissionais nas cinco praças (Rio de Janeiro, São Paulo, Belo Horizonte, Brasília e Recife) ${ }^{8}$. Na praça de São Paulo, foram trinta demissões ${ }^{9}$.

Para sair da situação pré-falimentar, a CBN insistiu na sua linha editorial voltada para um público de classe A e B, acima de 30 anos (TAVARES, 2006). A persistência em forma e conteúdo é a principal maneira para que o ouvinte identifique uma emissora e a CBN é uma rádio de formato informativo. Como tal, precisa fornecer conteúdos para que seu público-alvo fique cada vez mais próximo:

Na realidade, toda palavra comporta duas faces. Ela é determinada tanto pelo fato de que procede de alguém, como pelo fato que se dirige a alguém. Ela constitui justamente o produto da interação do locutor e do ouvinte. Toda palavra serve de expressão a um em relação ao outro. [...] A palavra é uma espécie de ponte lançada entre mim e os outros. Se ela se apoia sobre mim numa extremidade, na outra apoia-se sobre o meu interlocutor. (BAKHTIN, 1986, p. 113) 
Como já foi descrito, quando a família Marinho voltou os olhos para o SGR, viu uma empresa que precisava se adequar à política empresarial do grupo e, ao perceber o prestígio da CBN, foi necessário controlar o que iria ao ar. O jornalista Giovanni Faria ingressou na CBN em abril de 2000, como gerente nacional de jornalismo, segundo cargo na hierarquia. Para ele, um dos objetivos da nova gestão era aproximar as práticas das emissoras dos processos realizados no jornal.

\begin{abstract}
O Agostinho [ex-diretor de Jornalismo da CBN] chegou em janeiro de 2000 e eu em abril. O Paulo Novis [ex-diretor geral do SGR] foi para o SGR fazer uma engenharia de custo, a situação era dramática. Era necessário fazer um acompanhamento editorial efetivamente. Eu tinha 17 anos de jornal O Globo. Lá, os processos eram claros e estratificados, as chefias eram delimitadas de forma clara. Ao chegar à CBN, nosso briefing era dar um choque de ordem editorial. A dificuldade era que nós não éramos oriundos do rádio, mas, no jornal, lidávamos com muitas pessoas, em diferentes graus de hierarquia. Outra medida que precisávamos implantar era o aspecto de colaboração que havia no jornal. No SGR havia feudos claros. CBN e Globo eram irmãos inimigos. [...] A CBN virou a menina dos olhos dos acionistas, por causa do êxito comercial que começava a acontecer e por causa do prestígio da emissora com os chamados formadores de opinião. (Informação verbal) ${ }^{10}$
\end{abstract}

Breed afirma que os dirigentes são os responsáveis pela manutenção da política empresarial das organizações. O autor divide as empresas em dois grandes grupos: publishers, grupo formado pelos proprietários e seus executivos; e staffers, redatores e repórteres.

Uma vez que a política editorial é determinada pelos executivos, é óbvio que eles não podem recolher e escrever pessoalmente as notícias. Têm que delegar essa tarefa aos staffers e é nesta altura que as atitudes ou interesses dos staffers podem - e é o que acontece muitas vezes - entrar em conflito com as dos executivos. (BREED, 1993, p. 153)

Os departamentos de jornalismo lidam com um material extremamente instável - as notícias, que são imprevisíveis. "As decisões acerca da cobertura 
noticiosa devem ser tomadas rapidamente, com pouco tempo para discussões e tomadas de decisão em grupo" (SOLOSKI, 1993, p. 92). No rádio algumas características do veículo como simultaneidade e instantaneidade deixam ainda mais difícil controlar o que vai ao ar:

Outro aspecto que nos angustiava era a impossibilidade de controle de tudo que ia ao ar. No jornal você controla os processos e o conteúdo, no rádio você demora a entender que não dá para fazer o mesmo. Eu ouvia a rádio compulsivamente para poder dar conta. Eu falava com as chefias que ouvir a rádio já era um trabalho. Se você não estivesse em reunião ou despachando alguma coisa, deveria ouvir a rádio. (Informação verbal) ${ }^{11}$

Kunczik (2002) aplica no jornalismo o conceito de socialização na profissão. A socialização pode ser definida como o processo em que se transmite o conhecimento social necessário para desempenhar papéis num sistema social e consequentemente, seu controle:

Aplicada ao jornalismo, significa o aprendizado das habilidades, dos motivos, modelos de orientação e emoções requeridos para o funcionamento jornalístico cotidiano, noutras palavras, a adoção de normas, valores, costumes e atitudes que prevalecem nos meios de comunicação e que são necessários para a pessoa se tornar um membro (jornalista) maduro da organização. (KUNCZIK, 2002, p. 154)

Giovanni Faria explica algumas das estratégias usadas pelos dirigentes da CBN entre 2000 e 2001 para promover essa socialização da profissão na emissora, época em que já havia afiliadas pelo Brasil. Foram organizados seminários nas praças, com chefes locais conhecendo as outras regionais para chegar a uma unidade de processos. Antes mesmo da chegada de Agostinho Vieira à direção de jornalismo da CBN, em 2000, houve alguns esforços para organizar o jornalismo da emissora.

A CBN foi a primeira rádio brasileira a implantar com sucesso o formato all news. Não tocava música, não fazia transmissões esportivas, nem 
tinha programas do gênero magazine, era "a Rádio que toca notícia" dia e noite. Foi também a primeira rádio informativa do país a produzir uma programação inteira em rede nacional. (MEDITSCH, 2001, p. 60)

Uma forma de homogeneizar a prática dos integrantes da equipe é a criação de manuais de redação. O SGR publicou três versões desse conjunto de regras: em 1997, lançou um que deveria ser empregado em todas as emissoras (SILVEIRA, 1997); em 2006, houve uma publicação comemorativa dos 15 anos da CBN que, além de fatos históricos, trazia algumas regras a serem seguidas pelos profissionais que lá atuavam (TAVARES; FARIA, 2006); e, finalmente, em 2011, foi lançado um manual de redação da CBN, voltado diretamente para as práticas profissionais da emissora, explicando organograma, o que se espera dos profissionais que trabalham na rádio e a política editorial do grupo (TAVARES, 2011). Mauro Silveira, que ocupou o cargo de coordenador de jornalismo da CBN entre 1996 e 2004, organizou o manual de 1997, o primeiro do SGR. Ele explica o contexto em que nasceu o primeiro manual de jornalismo do SGR:

No ano que eu entrei mudou o diretor-geral e eu entrei praticamente com o Paulo Novis, que entrou com uma preocupação de sanear financeiramente lá. Ele veio com uma preocupação de integrar as emissoras ao comando das Organizações Globo, porque o histórico era quase de uma administração paralela sem que as pessoas prestassem muita obediência. (Informação verbal) $^{12}$

Um método que as direções de empresas burocráticas estabelecem para controlar a ação de seus funcionários é criar regras e regulamentos, mas no campo do jornalismo esse tipo de atitude é ineficaz principalmente por três razões, de acordo com Soloski. 1) as regras teriam que cobrir todas as situações que os jornalistas podem encontrar; 2) as regras são prescritivas e limitariam a capacidade de lidar com o inesperado; e 3) a direção de jornalismo teria que criar meios dispendiosos 
e ineficientes para ensinar a jornalistas regras e regulamentos. Silveira explica que o manual era uma tentativa de dar uma unidade de conteúdo à Rede CBN:

Chegou um diretor chamado Edgar Lisboa, com recomendação da ANJ, já havia trabalhado na agência JB aqui no Rio de Janeiro, e me colocou como supervisor nacional. Dentro desta função eu cuidaria da qualidade editorial do que iria ao ar. E ele me encarregou de fazer o manual. Este manual fazia todo sentido porque teoricamente a CBN era uma rede, mas editorialmente, não. Cada praça fazia a seu modo. (Informação verbal) ${ }^{13}$

Essa aproximação da CBN com a linha editorial do restante do Grupo Globo tem uma característica marcante no ar: a presença maciça de comentaristas. A emissora começou a ganhar prestígio com políticos e formadores de opinião e isso chamou atenção dos acionistas. Na virada dos anos 1990 para os anos 2000 entraram muitos dos comentaristas que estão na emissora até hoje. Marco Antônio Monteiro relembra quando a voz dos comentaristas se fez mais presente na CBN:

\begin{abstract}
A opinião chega quando $O$ Globo, por intermédio de Agostinho, desembarca em 2000. Antes havia algumas coisas, por exemplo, na crise do câmbio em [19]99, a direção de jornalismo ligou dizendo que o então ministro da Fazenda, Pedro Malan, havia pedido que a CBN parasse de dar informações sobre a disparada do dólar, pois estava provocando pânico nos investidores. O Agostinho passa a trazer o direcionamento editorial do Grupo Globo, principalmente através dos comentaristas. (Informação verbal) ${ }^{14}$
\end{abstract}

Os comentaristas de rádio funcionam como os colunistas nos jornais. Não representam inteiramente a opinião da emissora, mas, pensando nos mecanismos de controle das equipes que as empresas tentam colocar em prática, além de formadores de opinião, esses colunistas produzem conteúdos pelo menos aceitos, quando não totalmente de acordo com a linha editorial da organização jornalística. 


\section{Considerações finais}

Entre 1991 e 2000, a CBN passou por uma série de transformações em sua linha editorial. A emissora surgiu como uma das tentativas do oligopólio Globo de tomar conta da unidade de negócios de rádio. Fundado em 1944, com a inauguração da Rádio Globo, o SGR era visto no grupo, de acordo com a percepção dos entrevistados para este artigo, como uma unidade à parte. A TV Globo tinha a importância financeira pelos excelentes resultados comerciais e altos índices de audiência; o jornal $O$ Globo era detentor de prestígio junto aos empresários e políticos, mas o rádio era um veículo quase à margem. Em seus primeiros anos de vida, a CBN gozava de relativa autonomia, não tendo nem no nome, tampouco na logomarca, algo que a identificasse como veículo do Grupo Globo.

A partir da segunda metade dos anos 1990, o prestígio da rádio, principalmente na capital federal, despertou o interesse dos donos. Neste momento houve a aproximação de profissionais que atuavam em outras empresas do grupo para implantar a cultura corporativa do Grupo Globo. O caso relatado pelo ex-gerente nacional de jornalismo, Marco Antônio Monteiro, de que no meio da crise cambial de 1999 o Ministério da Fazenda pediu que a emissora parasse de noticiar a disparada da moeda americana, é emblemático. Ao aceitar o pedido das autoridades cambiais, a direção da emissora fez um conluio com os poderes político e econômico para mascarar a realidade em detrimento da informação verdadeira e relevante ao interesse público. Conforme escreveu Soloski (1993) essa nova política da emissora tem como resultado uma cobertura noticiosa que não ameaça nem a posição econômica da organização jornalística, nem o sistema político-econômico global no qual a organização jornalística opera.

A direção do Grupo Globo resolveu organizar a CBN para que a ação desse subsistema não criasse constrangimentos para o sistema complexo que é o oligopólio dos Marinho. A produção de notícias leva em conta também a política editorial da organização jornalística: 
órgão informativo e dos jornalistas. Isso significa que os critérios de relevância são, por um lado, flexíveis e variáveis quanto à mudança de certos parâmetros e, por outro, são sempre considerados em relação à forma de operar do organismo que faz a informação. (ALTHEIDE, 1976, p. 223-226 apud WOLF, 2003, p. 193)

Diante dos argumentos citados neste artigo, seria difícil pensar que hoje em dia um oligopólio como o Grupo Globo permitisse que o produto estratégico representado por uma rádio jornalística nascesse sob o signo da autonomia editorial como foi o caso da CBN. Os mecanismos de controle se aperfeiçoaram. Hoje, não existe apenas a perda de autonomia editorial da emissora em relação ao Grupo Globo, há também a questão mais específica do trabalho do jornalista. No rádio, de certa forma, os repórteres sempre tiveram mais liberdade na redação das reportagens, uma vez que a necessidade de apurar a matéria e divulgar o quanto antes fazia com que os controles fossem mais frouxos. Porém, nesses tempos de sociedade vigiada por todos os lados, mesmo que os comandantes das empresas não consigam ouvir tudo o que vai ao ar ou é publicado nos ambientes digitais das emissoras, a ação do público amplia esse controle. O ouvinte que tem críticas sobre o que é veiculado conta com diversos canais para expressar esse descontentamento, mais do que anteriormente, quando a interação se dava por telefone fixo ou carta. Hoje, as chefias têm mais instrumentos de vigilância do que vai ao ar, podendo manter com mais facilidade a homogeneização editorial, reforçando a política de comunicação da empresa.

\section{Referências}

BAKHTIN, M. Marxismo e filosofia da linguagem. São Paulo: Hucitec, 1986.

BOLAÑO, C.; BRITTOS, V. A televisão brasileira na era digital: exclusão, esfera pública e movimentos estruturantes. São Paulo: Paulus, 2007. 
BREED, W. O controle social da redação. In: TRAQUINA, N. (Org.). Jornalismo: questões, teorias e "estórias". Lisboa: Vega, 1993. p. 152-166.

BRITTOS, V.; GASTALDO, E. Mídia, poder e controle social. Alceu, Rio de Janeiro, v. 7, n. 13, p. 121-133, 2006. Disponível em: https://bit.ly/3eqnKYC. Acesso em: 29 jun. 2018.

BUCCI, E. A rádio que toca o Brasil. In: TAVARES, M. Manual de redação da CBN. São Paulo: Globo, 2011. p. 11-17.

CAMPOS, R. De patinho feio a cisne para anunciantes. In: TAVARES, M.; FARIA, G. (Org.). CBN, a rádio que toca notícia: a história da rede e as principais coberturas, linguagem e estilo do all news, jornalismo político, econômico e esportivo, a construção da marca, o modelo de negócios. Rio de Janeiro: Editora Senac Rio, 2006. p. 56-61.

FERRARETTO, L. A. Rádio: o veículo, a história e a técnica. Porto Alegre: Sagra Luzzatto, 2001.

GASPARI, E. A ditadura escancarada. São Paulo. Companhia das Letras. 2002.

KUNCZIK, Michael. Conceitos de jornalismo. São Paulo: Edusp, 2002.

LEITÃO, M. Economia instantânea. In: TAVARES, M.; FARIA, G. (Org.). CBN, a rádio que toca notícia: a história da rede e as principais coberturas, linguagem e estilo do all news, jornalismo político, econômico e esportivo, a construção da marca, o modelo de negócios. Rio de Janeiro: Editora Senac Rio, 2006. p. 90-101.

MARINHO, J. R. Rádio como exercício de cidadania. In: TAVARES, M.; FARIA, G. (Org. . . CBN a rádio que toca notícia: a história da rede e as principais coberturas, 
linguagem e estilo do all news, jornalismo político, econômico e esportivo, a construção da marca, o modelo de negócios. Rio de Janeiro: Editora Senac Rio, 2006. p. 14-18.

MEDITSCH, E. O rádio na era da informação: teoria e técnica do novo radiojornalismo. Florianópolis: Insular: Editora da UFSC, 2001.

SILVEIRA, M. (Org.). Manual de redação do Sistema Globo de Rádio. Rio de Janeiro: Globo, 1997.

SOLOSKI, J. O jornalismo e o profissionalismo: alguns constrangimentos no trabalho jornalístico. In: TRAQUINA, N. (Org.). Jornalismo: questões, teorias e "estórias". Lisboa: Vega, 1993.

TAVARES, M. Manual de Redação da CBN. São Paulo: Globo, 2011.

TAVARES, M. Ingredientes de uma receita que deu certo. In: TAVARES, M.; FARIA, G. (Org.). CBN, a rádio que toca notícia: a história da rede e as principais coberturas, linguagem e estilo do all news, jornalismo político, econômico e esportivo, a construção da marca, o modelo de negócios. Rio de Janeiro: Editora Senac Rio, 2006. p. 90-101.

TAVARES, M.; FARIA, G. (Org.). CBN, a rádio que toca notícia: a história da rede e as principais coberturas, linguagem e estilo do all news, jornalismo político, econômico e esportivo, a construção da marca, o modelo de negócios. Rio de Janeiro: Editora Senac Rio, 2006.

WOLF, M. O newsmaking: critérios de importância e noticiabilidade. In: WOLF, M. Teorias da comunicação. Lisboa: Presença, 2003. p. 177-252. 